\title{
Stabilizing global temperature change below thresholds: Monte Carlo analyses with MERGE
}

\author{
Socrates Kypreos
}

Published online: 22 February 2007

(C) Springer-Verlag 2007

\begin{abstract}
Policies may help to keep the anthropogenic temperature change below some critical temperature thresholds. We apply MERGE in a probabilistic risk assessment framework to assess the risk of action versus inaction on climate change. The method applied gives a probabilistic assessment of the associated economic costs and levels of carbon-values and emissions reduction, as well as the needed technological change to restructure the energy system. The study suggests that a set of low-carbon and carbon-free technologies has to be developed and diffused around the world in order to reduce the risk of serious, adverse climate change. Eventually, a mass deployment of biomass farming technologies for bio-fuels and/or hydrogen production, in conjunction with carbon capture and sequestration options, are needed to satisfy the EU threshold of $2^{\circ} \mathrm{C}$ average atmospheric temperature rise above the pre-industrial temperature levels by the year 2100 . However, because this temperature threshold represents a severe target, the global "willingness-to-pay" (WTP) must be significantly improved in relation with present attitudes.
\end{abstract}

Keywords Probabilistic risk assessment - Carbon mitigation policies . Temperature thresholds

\section{Introduction}

Article 2 of the UN Framework Convention on Climate Change (FCCC) aims to "stabilize greenhouse gas (GHG) concentrations in the atmosphere at a level that would prevent dangerous anthropogenic interference with the climate

\footnotetext{
S. Kypreos $(\bowtie)$

Energy Economics Modeling Group, Paul Scherrer Institut, 5232 Villigen-PSI, Switzerland e-mail: socrates.kypreos@psi.ch
} 
system" and refers explicitly to ecosystems that can adapt naturally to climate change, to food production that is not threatened and to economic development that will be capable to proceed in a sustainable manner.

A considerable increase of scientific publications has occurred over the last years where the uncertainty related to climate sensitivity (CS) is taken into account when either a baseline or a cost-benefit analysis (CBA) scenario is quantitatively elaborated. Also, these recent studies (described in Sect. 3) seek to establish risk functions that describe the likelihood of overshooting different critical targets on temperature change (e.g., $2^{\circ} \mathrm{C}$ above pre-industrial levels) based on the probability density functions (PDFs) related to climate sensitivity.

The Third Assessment Report (IPCC TAR 2001) adopted a range of temperature change between 1.5 and $4.5^{\circ} \mathrm{C}$ to describe climate sensitivity, but failed to assign distribution probabilities to these temperature-change values for the different SRES scenarios (Nakicenovic and Swart 2000). Recent publications described in Sect. 3, define the climate sensitivity in terms of PDF assuming temperature changes greater than $4.5^{\circ} \mathrm{C}$, but with low probability of occurrence. These PDF-based CS estimates open the possibility of exploring risk-based approaches to related scenario research as for example reported by Nordhaus (1999), Tol (2003), Webster et al. (2003), Mastrandrea and Schneider (2004), Yohe et al. 2004, wherein random distributions were assumed not only for "physical" parameters such as CS but also for socio-economic drivers.

Studies of the impacts of global warming and of energy-policy analyses have also used stochastic models (Fankhauser 1994; Manne et al. 1995) by applying aggregated global models like DICE (Nordhaus 1993) and CETA-R (Peck and Teisberg 1995). The study by Fragnière and Haurie (1996) is the first to introduce the stochastic approach in large-scale bottom-up energy models like MARKAL while Segberts et al. (2000) was the first to introduce Monte Carlo techniques into a MARKAL model of Europe. Petersen (2006) gives a survey of approaches and findings for uncertainty and economic analysis of climate change.

The present work is an extension of a stochastic analyses performed with MERGE (Richels et al. 2004) to study the effectiveness and impacts of globalwarming mitigation policies. Work with stochastic analysis is based on the act, then learn principle in decision analyses as uncertainty is resolved in the future. The act, then learn approach assumes that a few "states of the world"(SOW) represent uncertain input parameters, with subjective probabilities attached to each SOW while present-day uncertainty is assumed to be resolved in the future. The expected cost (utility) is then minimized (maximized) to define a set of control variables for the period prior the resolution of uncertainty. Through such an analysis, a "hedging" policy that deals with uncertainty can be defined (i.e., "act") in periods prior the resolution of uncertainty (i.e., "then learn") in a way that minimizes the expected losses.

In the probabilistic risk assessment (PRA) analyses applied in this study, we exclude the possibility of having a resolution of uncertainty in the future, since "details of climate and weather will remain unpredictable to some degree" (Webster et al. 2003). Decisions can be made based on the precautionary 
principle, however, wherein we proceed with a policy that allows us to avoid a given risk of action or inaction. In such a case, conclusions must be revised as long as knowledge on future uncertainty improves. The above characteristic is the main advantage of combining PRA with integrated assessment models like MERGE.

The present study extends the version of MERGE used for uncertainty analyses by incorporating Monte Carlo (i.e., random) algorithms and parameters that describe socio-economic driving forces defining future $\mathrm{CO}_{2}$ concentration levels and the related climate sensitivity. The output of such analyses is a probability distribution that indicates the likelihood of different long-term outcomes either in terms of temperature change or through energy and socioeconomic indicators that aid in assessing the risks of action or inaction in relation to climate change.

The research questions we try to address with a probabilistic assessment methodology are the following:

- What is the risk that the temperature rise will exceed given critical thresholds of climate change?

- What is the appropriate willingness-to-pay (WTP), or the carbon-tax level, when cost-benefit is applied to reduce the risk of overshooting these critical thresholds?

- What are the GHG concentrations required for stabilization, and the emission pathways required to achieve the needed concentrations?

- What are the technological options of meeting different stabilization levels of GHGs in the atmosphere?

The first question to be asked is how these thresholds are established and how they can be justified. The German Advisory Council on Climate Change (WBGU 2003) concluded that the present state of science is not sufficient advanced to quantify what "dangerous anthropogenic interference with the climate system" exactly means and instead proposes that the overall global temperature increase should not exceed $2^{\circ} \mathrm{C}$ above pre-industrial levels while the European Council asked the Community and its Member States to consider mid- and longer-term emission-reduction strategies (EU Council, 7631/04). The justification for this policy target is based on arguments related to the expected impacts on nature, ecosystems and human beings (Meinshausen 2005). The question of trade-offs arises if one adopts a less-severe policy target. For researchers having an economic background, the target is conservative, in that they typically argue that strong emission reductions will invoke dangerous economic impacts (Tol and Yohe 2006). Others claim that the Kyoto protocol requires too much emissions reduction too early (Manne and Richels 1999). Still others, however, do not even conclude that a temperature increase of $2^{\circ} \mathrm{C}$ above pre-industrial levels is 'safe' enough (Meinshausen 2005).

For these reasons, the present study not only focuses on the risk of overshooting global mean- temperature rise by $2^{\circ} \mathrm{C}$ above pre-industrial levels, but also considers alternative targets. Mastrandrea and Schneider (2004) discussed the issue of dangerous anthropogenic interference (DAI) in relation to climate 
policy. They developed a metric for determining dangerous interference with the climate system based on the "reasons for concern" presented in the IPCC's Synthesis Report. The median, 50th percentile threshold in this metric is $2.85^{\circ} \mathrm{C}$ above year 2000 levels. This temperature level is an alternative (but still arbitrary) threshold, i.e., an average of impacts accumulating across all metrics applied in the IPCC study, ${ }^{1}$ examined in our study.

The model used in our risk assessment study is a simplified version of MERGE5.1 with only two world regions (i.e., North and South), a formulation of CS based on probability density functions, an endogenous treatment of the ocean diffusivity and an endogenous representation of technological change. The latter considers the implementation of advanced, carbon-free technologies to penetrate gradually present energy markets and thereby to provide sustainable means of energy alongside the diminishing use of conventional fossil fuels (i.e., oil and gas) and to control the increase of carbon dioxide concentrations in the atmosphere.

The CS term covers the uncertainty in temperature rise (i.e., feed-backs because of clouds, water vapour and related increases in global albedo) when the pre-industrial GHG concentration in the atmosphere doubles. The random samples of stochastic input data include variations in socio-economic growth projections, the decoupling between energy consumption and economic growth and the learning rates. Variations in these kinds of input lead to different emissions scenarios, GHG concentrations, and, hence, changes in global temperature rise. The development of the energy sector and the induced technological change is determined endogenously to the model and generally represents an optimistic view of energy futures. We do not claim that these scenarios cover the full range of possible future outcomes, since the socio-economic development and the technological options to react against global warming are generally optimistic, but we believe that a significant (realistically encompassing) variation of development pathways is represented in the analyses reported herein.

Since the discounting of future benefits versus near-term costs (investments) to mitigation polices is controversial, two different approaches are used to define the utility discount rate. Similarly, since the climate sensitivity issue represents the most significant uncertainty, we apply both conservative and optimistic density functions in the analysis. These alternative assumptions on PDFs for CS and in the discounting principles makes necessary of at least four Monte Carlo (MC) runs for each combination of input parameters selected.

Finally, the Latin Hypercube Sampling (LHS) method was applied to reduce the variance of statistical estimates for model outputs like the carbon value; the induced temperature change; the welfare loss; the emissions profiles; the GHGs concentrations and forcing, and the primary fuel share needed to establish the

\footnotetext{
1 According to the synthesis chapter of IPCC WG2 (Smith et al. 2001), there are four reasons to concern about climate change. The report considers a broad range of temperature limits as some stakeholder groups ask for immediate stringent emissions controls (e.g., small island communities); while others would tolerate some more warming. Thus, it is not possible to define a commonly acceptable threshold.
} 
proposed socio-economic system changes and equilibrium behaviour under the cost benefit analysis (CBA). Latin hypercube sampling for large scale optimization models applied together with MC Analyses is an established approach for defining the expected values of variables that model physical or economic/technological systems. To obtain meaningful statistical results at a reasonable computational cost, a variance reduction method is applied when estimating the expected values. The Latin Hypercube Sampling routine (distributed by the Sandia National Laboratories), is a FORTRAN program of R. L. Iman and M.J. Shortencacier, publicly available (NUREG/CR-3624, SAND83-2365, RG, March 1984). The LHS program prepares constrained random samples of stochastic input data for each set of variables needed to perform MC runs. Then MERGE defines the CBA equilibrium by maximizing the global welfare and establishes the model output. Our analysis with MERGE needs for each specific combination of $\mathrm{CS}$, discount rate, the Baseline and two willingness to pay (WTP) levels, 12 different MCA simulations (i.e., $2 \cdot 2 \cdot 3$ cases) with 250 optimizations each case and it takes $400 \mathrm{~min}$ on a $3 \mathrm{GHz}$ PC to complete all of them. All these optimization runs are executed as CBA cases since cost-efficient analyses, e.g., imposing a constraint of $2^{\circ} \mathrm{C}$, would have been infeasible for most of the cases. To increase the efficiency of the MCA algorithm, the model calibration and initialization, the MCA loop and the statistical analyses of output are programmed directly in GAMS. The results are stored on EXCEL files for subsequent statistical evaluation.

The remaining of the paper is organized as follows:

Section 2 discusses the changes in the version of MERGE required for MCA and describes key input random parameters, given that the MERGE model per se (Manne et al. 1995; Kypreos 2005) is well known. These later points refer to population and economic development; the decoupling between economic growth and energy demand; the treatment of climate sensitivity and the learning rates. The formulation of damage functions and the WTP, the utility function and its discounting rate are defined with two alternative input parameters. Assumptions concerning technologies are also explained in this section.

Section 3 describes results related to equilibrium temperature change as function of the PDFs assumed in the study and of carbon stabilization levels expressed in terms of constant $\mathrm{CO}_{2}$-eq atmospheric concentrations. Also, confidence levels are given for the transient temperature change for different future years. This procedure is performed by applying the same simple relation between concentration changes, forcing and transient temperature change as adopted in the MERGE model.

Section 4 presents results for the baseline cases (i.e., without policies to control anthropogenic carbon emissions) that varies only the socio-economic and energy related assumptions, and the CS. Results such as energy use, emissions, concentrations, forcing and the risk of overshooting given critical levels of temperature change are presented.

Section 5 presents the probabilistic CBA for two different PDFs [i.e., the first from Wigley and the second from Knutti et al. (2003)] analysed with descriptive and prescriptive utility discount rates. Similar results are given as for the 
baseline case, but in the CBA runs new information is included, such as the carbon value and the fraction of consumptions that consumers are willing to pay to avoid climate damages.

Finally, Sect. 6 discusses the key results of the analyses with MERGE and summarizes the main conclusions of the study.

\section{Modeling framework}

\subsection{General model description}

MERGE is a Model for Evaluating the Regional and Global Effects of GHG reduction policies. We have reduced the regional representation of the latest available version of MERGE5.1 to two geopolitical regions: North, which includes OECD Europe, USA, Japan, Canada, Australia and New Zealand, Eastern Europe and the former Soviet Union; and South, which includes China, India, Mexico, the OPEC nations, and the rest of the world (ROW).

An ETA-MACRO model describes each of these two regions. The energy model ETA is a "bottom-up" engineering model that describes the energy-supply sector of a region, including the production of non-electric energy (fossil fuels, synthetic fuels, and renewables) and the generation of electricity. The ETA model captures price-dependent substitutions of energy forms (e.g., switching to low-carbon fossil fuels) and energy technology substitution (e.g., the use of renewable-energy instead of fossil-fuel systems) to achieve specified $\mathrm{CO}_{2}$ reduction targets.

The MACRO sub-model is a "top-down" macro-economic growth model that balances the non-energy part of the economy of a given region using a nested constant-elasticity-of-substitution (CES) production function. The MACRO model also captures autonomous (e.g., price-independent) effects and macroeconomic feedbacks between the energy sector and the rest of the economy, such as the impacts of higher energy prices (e.g., resulting from $\mathrm{CO}_{2}$ control policies) on economic activities. The mathematical formulation of the regional ETA-MACRO sub-models translates into a non-convex, non-linear, optimization problem, where the economic equilibrium is determined by a single optimization. Finally, inclusion of a simple climate and damage model transforms MERGE into an Integrated Assessment Model (IAM). The MERGE model considers both market (through production losses) and non-market damages (through losses in global welfare).

The MERGE model maximizes a welfare function defined as the net present value of the logarithm of regional consumption adjusted for the non-market damages. Included in the wealth of each of the two regions modeled by MERGE are initial endowments of fossil fuels, renewable energy sources, and $\mathrm{CO}_{2}$ emission permits.

The regional ETA-MACRO sub-models are linked in MERGE, which aggregates the regional welfare functions, adjusted for the non-market damages, into a global welfare function using appropriate Negishi weights (Negishi 1972). 
Also, global trade constraints applied in each period ensure that international trade of commodities is balanced. Regional technological learning with global spillovers, climate-change impacts and the associated market and non-market damages further enhance the regional links and interactions.

The MCA loop in MERGE is organized as follows:

(a) Pre-solving

The critical and uncertain input parameters are identified and the related PDFs are specified. A specific sampling method (i.e., Latin Hypercube Sampling) defines the set of input parameters for each Monte Carlo run and the data so generated are stored in a table. The length of this table equals the number of MC optimizations to be performed. We then rank the input vector with the CS as the key parameter for ranking. This is because smooth variations of CS accelerate convergence within MERGE and helps to avoid infeasibilities. The stochastic parameters estimated in this way are the climate sensitivity (CS); the population level; the per capita income in north and south for the year 2100; the AEEI factor and finally the fraction of learning rate to be applied.

(b) The MCA loop:

(1) With the help of each stochastic vector of input variables we define the socioeconomic input, the energy related data, the CS value and the ocean diffusivity for MERGE. Then, the model is calibrated for each new set of input data, the matrix of the problem is defined and the search for optimality begins starting from the levels of the previous solution.

(2) If an optimal solution is obtained, selected output variables are stored for each time step and iteration. This refers to the induced climate forcing; the temperature change; the macro-economic variables of investments and consumption; the welfare loss of consumption related to the equilibrium carbon value; the cost of mitigation and the damages; the emissions profiles; the GHGs concentrations; the primary fuel share and electricity production by technology.

(3) Any source of infeasibility identified during the course of the study has been removed before performing the final MC runs. If, in spite of this pre-conditioning, infeasibilities appear during the MCA loop, the optimization is executed again for the problematic vector of input, starting another search for optimality from the beginning, until a solution is found.

(4) If this specific set of input data will eventually produce an infeasible or non-optimal solution, and the number of infeasibilities remains below a threshold, it is excluded from the sampling and we continue the loop with the next vector of input data. Otherwise, we continue with (5).

(5) If the number of infeasibilities is above a threshold of, i.e., one over 250 optimizations, we interrupt the analyses without storing the information, we investigate the cases where the model failed, removing the source of infeasibilities and start the MCA from the beginning. Since the maximum number of infeasible/non-optimal cases is restricted to one out of 250 optimizations, the results obtained are assumed to be unbiased. 
(c) Post-solving

At completion of the loop, statistical parameters like the mean, the variance, the standard deviation, the kurtosis and skewness are defined. Based on the identified values of the mean, and the variance, the results for each stochastic output are processed to define its PDF function for each time period. In doing that we count the number of occurrences for the variable in examination within 100 equally spaced intervals around the mean. The CPDFs thus estimated are stored and appear in this report, as, e.g., in Fig. 11.

\subsection{Technology description}

A significant number of technological options modeled in MERGE lead to more efficient and clean energy systems that emit either less $\mathrm{CO}_{2}$ per unit of energy or do not emit carbon at all. Also, options that remove carbon from the atmosphere via biomass farming combined with carbon capture and sequestration (CCS) are considered. The following options have been modeled, with the more important options being described explicitly in Table 1:

1. Energy efficiency improvement options simulated either as price independent or as price dependent relations.

2. Inter-fuel substitution for electric and non-electric markets (e.g., more gas than coal).

3. Zero-carbon electricity from wind turbines, nuclear plants and solar PV.

4. Zero-carbon fuels from biomass.

5. Carbon capture and sequestration (CCS) in underground storage.

6. Biomass farming for energy production with and without CCS.

A few energy technologies are treated explicitly as for instance carbon-free power plants, high-cost Solar-PV or low-cost Wind, or plants producing lowcost, non-electric energy from renewables (RNEW). Table 1 lists the technologies modeled in MERGE, with the first set of technologies corresponding to power generation, and the second set of technologies referring to a non-electric energy system.

Technological learning describes the reduction in the specific cost of a given technology as a result of the accumulation of knowledge (e.g., operating experience). A learning curve for a given technology relates the specific cost of that technology to one or more factors describing the accumulation of knowledge in that technology. In implementing these levels of cost reduction for each doubling of production, a barrier is introduced to represent a maximum possible reduction of generating cost until the floor cost is attained. We assume learning rates that induce a $4 \%$ (i.e., for new nuclear with a floor cost of $30 \mathrm{mills} / \mathrm{kWh}$ ), $10 \%$ (i.e., for wind with a floor cost of 35 mills $/ \mathrm{kWh}$ ) and $20 \%$ (i.e., for solar PV with a floor cost of $40 \mathrm{mills} / \mathrm{kWh}$ ) cost reduction in power generation systems for each doubling in production, and a $10 \%$ rate for non-electric systems and a floor cost of $4.5 \$ / \mathrm{GJ}$. This reduction is applied to the learning part of the cost that equals the initial generating cost minus the floor cost, both given in the cost column of Table 1 . To avoid a detailed modeling of alternative nuclear fuel 
Table 1 Technologies used in MERGE and naming conventions

\begin{tabular}{|c|c|c|c|c|c|}
\hline Electric & Technologies & $\begin{array}{l}\text { Introduction } \\
\text { date }\end{array}$ & $\begin{array}{l}\text { Gen. Cost/ } \\
\text { Floor Cost } \\
(\text { mills/k Wh) }\end{array}$ & $\begin{array}{l}\text { Carbon } \\
\text { Emissions } \\
(\mathrm{kg} \mathrm{C} / \mathrm{k} \mathrm{Wh})\end{array}$ & $\begin{array}{l}\text { Learning } \\
\text { Rate }\end{array}$ \\
\hline HYDRO & $\begin{array}{l}\text { Hydroelectirc, and other } \\
\text { renewables }\end{array}$ & Existing & 40. & 0.0 & \\
\hline NUC & Remaining initial nuclear & Existing & 50. & 0.0 & \\
\hline GAS-R & Remaining initial gas fired & Existing & 35.7 & 0.1443 & \\
\hline OIL-R & Remaining initial oil fired & Existing & 37.8 & 0.2094 & \\
\hline COAL-R & Remaining initial coal fired & Existing & 20.3 & 0.2533 & \\
\hline GAS-N & Advanced combined cycle (AGC) & 2000 & 30.3 & 0.0935 & \\
\hline GAS-A & Gas-Fuel Cell with removal & 2020 & 47.7 & 0.0 & \\
\hline COAL-N & Pulverized Coal & 2000 & 40.6 & 0.1955 & \\
\hline COAL-A & Coal-FC with $\mathrm{CO}_{2}$ recovery & 2020 & 55.9 & 0.0068 & \\
\hline IGCC & IGCC with $\mathrm{CO}_{2}$ removal & 2020 & 62 & 0.024 & \\
\hline New Nuclear ${ }^{a}$ & Generic New Nuclear with LBD & 2010 & $55 / 35$ & 0.0 & 0.04 \\
\hline Wind $^{\mathrm{a}}$ & Wind with LBD & 2000 & $45 / 35$ & 0.0 & 0.10 \\
\hline SPV $^{\mathrm{a}}$ & Solar PV with LBD & 2000 & $95 / 40$ & 0.0 & 0.20 \\
\hline Non Electric & technologies & & US\$/GJ & tons $\mathrm{C} / \mathrm{GJ}$ & \\
\hline CLDU & Coal direct use & Existing & 2.5 & 0.0241 & \\
\hline OIL1-OIL10 & Oil categories & Existing & $3-5.25$ & 0.0199 & \\
\hline GAS1-GAS10 & 0 Gas categories & Existing & $2-4.25$ & 0.0137 & \\
\hline SYNF & Synthetic fuels & Existing & 8.33 & 0.04 & \\
\hline RNEW & Renewables & Existing & 6. & 0.0 & \\
\hline NEB-B ${ }^{\mathrm{a}}$ & $\mathrm{H}_{2} / \mathrm{F}-\mathrm{T}$ from Biomass, CCS, LBD & $2010-20$ & $19 / 4.5$ & -0.0216 & 0.10 \\
\hline $\mathrm{NEB}-\mathrm{F}^{\mathrm{a}}$ & $\mathrm{H}_{2} / \mathrm{F}-\mathrm{T}$ from coal, CCS, LBD & 2010-20 & $15 / 4.5$ & 0.0025 & 0.10 \\
\hline LBD-H ${ }_{2}^{\mathrm{a}}$ & $\begin{array}{l}\mathrm{H}_{2} \mathrm{f} \text { from carbon-free } \\
\text { source, LBD }\end{array}$ & $2010-20$ & $15 / 4.5$ & 0.0 & 0.10 \\
\hline
\end{tabular}

${ }^{\text {a All technologies with LBD could become available in 2010-2020. Floor costs apply to all LBD }}$ technologies as indicated

cycles and the depletion of nuclear resources, we have assumed that nuclear energy could contribute a maximum of $33 \%$ to the global electricity production. Similarly, each of the intermittent technologies, i.e., wind and solar PV, are able to provide a maximum of $20 \%$ of power generation. Also, the cumulative storage potential assumed for CCS is $600 \mathrm{GtC}$ at a cost of $10 \$ / \mathrm{tC}$.

Electric-generation backstop technologies consist of renewable sources, like wind, solar PV and new nuclear concepts. Non-electric energy-generation backstops are identified with the use of Fischer-Tropsch (FT) fuel or hydrogen, while the primary-energy source for these carbon-free energy carriers is either biomass or renewable electricity or nuclear. Biomass farming for hydrogen production with CCS (Azar et al. 2006) is being considered as key technology to achieve the policy in discussion. The biomass potential assumed is 400 $\mathrm{EJ} /$ year, while the removal rate of carbon emissions from the atmosphere is $0.0216 \mathrm{~kg} \mathrm{C} / \mathrm{GJ}$. The other key technology considered in this analysis is FT fuels produced from biomass or coal (SYNF). All other energy technologies (e.g., systems not exposed to learning by doing) and the non-learning part of backstop systems that corresponds to the floor cost, assume an autonomous cost reduction of $0.2 \%$ per annum. The learning function is coded directly as 
a non-linear and non-convex formulation. ${ }^{2}$ Learning technologies are assumed to be made available within the time frame 2010-2020 if they are competitive, while their penetration rates are increased to $13.5 \%$ per annum (i.e., above the standard value of $11.5 \%$ applied in the MERGE model). The learning rates in this study are treated as stochastic parameters that vary at random with a uniform distribution of $0-100 \%$ of their levels shown in Table 1.

\subsection{Population and regional Gross World Product (GWP) projections}

The level of GHG emissions for a given energy mix is proportional to economic activity which in turn is related to the growth in population and per-capita Gross World Product (GWP). Both population projections and GWP growth rates are exogenous input to the MERGE model. Through 2020, MERGE uses the projections from the "reference case" defined by the Energy Information Administration (EIA 2003). Thereafter, growth is extrapolated using logistic functions. The economic growth is random and is specified in such a way that in the year 2100, Annex B countries have a uniform distribution of GWP between 40 and 120 thousand USD per capita while the Non-Annex B countries have a uniform income level between 25 and 50 thousand USD per capita. The logistic curves need the specification of three points to be defined. Two of these points are the present level of economic activity and the expected value in the year 2100. Finally, each of these logistic functions converges in the very long run to the same income level for all world regions. This long term asymptote of economic output by region differs per scenario but is twice as much as the random value of GWP of Annex B countries in the year 2100. This value is high in comparison with current income of non-annex B countries and leads to significant variations of income per case.

Similarly, population increases from present levels to stabilize between 8 and 10 billions people following a uniform distribution. Most of the population growth takes place in the Non-Annex B countries.

As shown in Fig. 1 a significant range of GWP is covered in the MCA. For the year 2100 the GWP varies between 300 and 610 trillion \$ (with the purchasing power of 2000), while for the year 2150 GWP varies between 680 and 1800 trillions.

Energy use is expected to be correlated with the economic development described in Fig. 1, but MERGE assumes a price dependent and a price

\footnotetext{
2 There is no guarantee that MERGE identifies of global optimal solution with our formulation of endogenous learning when many technologies compete for market shares. However, the solver (i.e., CONOPT3) identifies appropriate NLP optimal solutions if we apply low and upper bounds to each learning technology. Bounds force a minimum initial technology penetration just above zero, as proposed by Manne and Barreto (2004) to avoid locking, and restrict solutions below a maximum possible penetration. Experience has shown that in such case the solver responds to input changes such that new solutions are always identified in favor of a technology with improved performance. The MIP option (Kypreos 2005) could have been an alternative approach that guarantees global optimal solutions but as long as an efficient restart option can not be applied, MIP is not appropriate for MCA.
} 


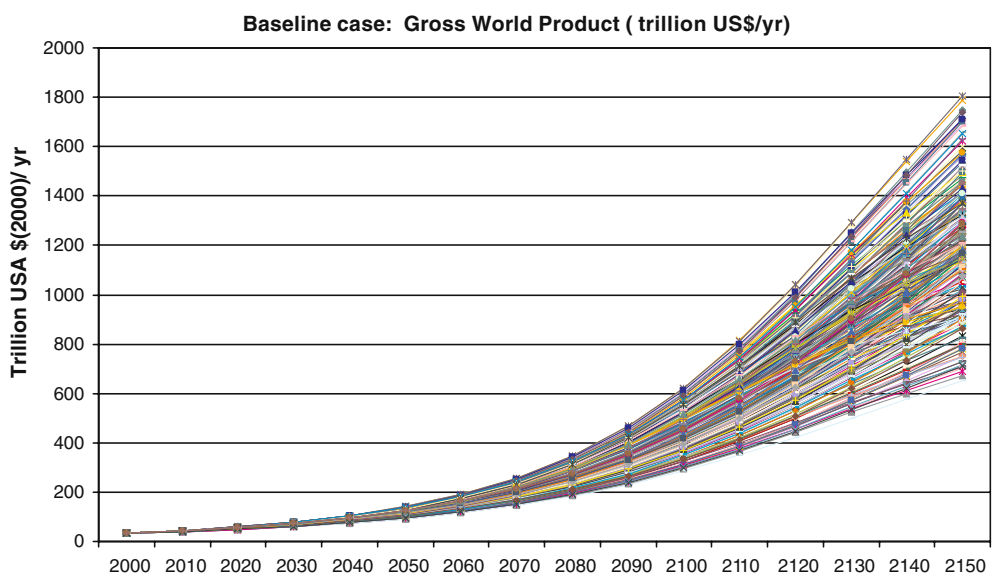

Fig. 1 GWP in trillion US Dollars with the purchasing power of 2000

independent (i.e., autonomous) decoupling rate between economic activity and energy use. The autonomous energy efficiency improvement (AEEI), i.e., the annual rate of decoupling between energy and economic growth is defined to be a fixed fraction of the regional growth. We assume a normal distribution function for the AEEI factor with a mean of 0.425 percent of the economic growth, while all other values are distributed normally between 0.4 and 0.45 percent of the economic growth with a $98 \%$ confidence level. Based on assumptions previously described, the induced primary energy use for the baseline case, as given by Fig. 2, varies between 1,400 and 2,100 EJ per year by the year 2100 (i.e., between 3.6 and 5.5 times the present energy consumption) while the growth rate of electricity is almost twice as high as this of primary energy consumption (i.e., with a mean of 9.6 times the present electricity production).

\subsection{The MERGE formulation of forcing and temperature change}

The temperature change evaluation resulting from the increased atmospheric concentration of GHGs is formulated based on post-2000 concentrations and begins with the specification of the radiative forcing.

The climate forcing, $\Delta F\left(W / m^{2}\right)$, resulting from changes in the $\mathrm{CO}_{2}$ concentrations is defined as the natural logarithm of the ratio of carbon concentrations between the pre-industrial equilibrium concentration $C_{0}$, and the current value $C_{t}$;

$$
\Delta F_{t}=5.35 \cdot \ln \left(C_{t} / C_{0}\right) .
$$

The long-term equilibrium mean-temperature change at the earth surface is assumed to be proportional to forcing and the climate sensitivity. The climate sensitivity $\Delta T_{2 x \mathrm{CO}_{2}}$ "is used as a metric for all important feedbacks, (i.e., albedo, clouds and water vapor), which potentially amplify the warming" 

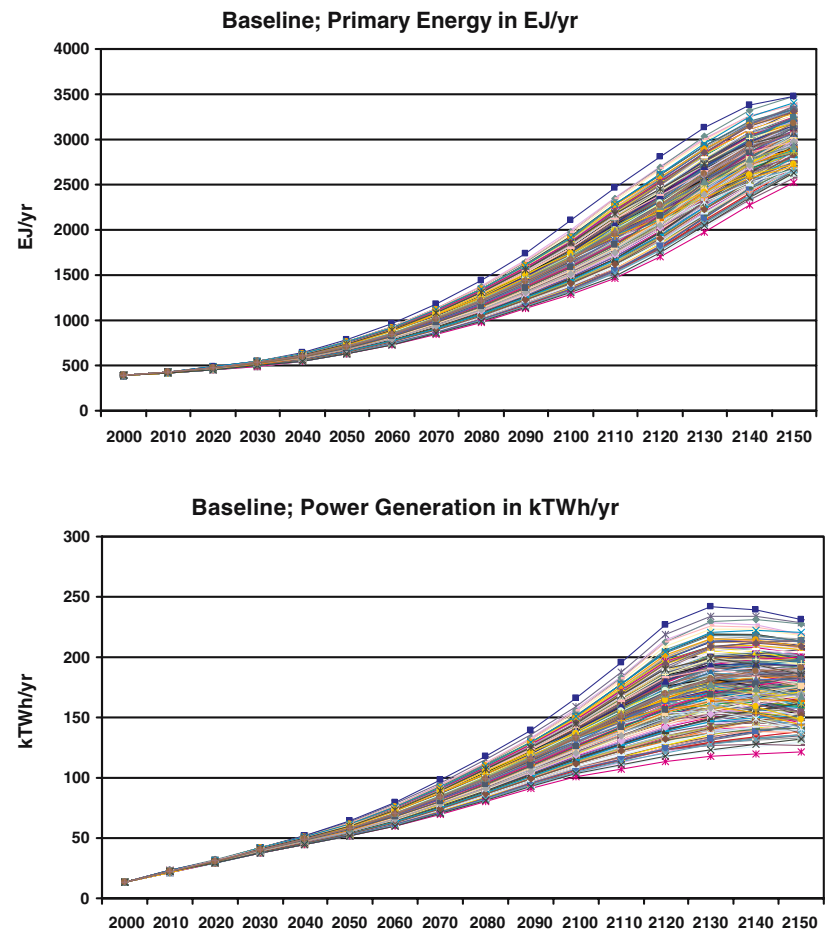

Fig. 2 Baseline case; Global primary energy and power generation

Knutti et al. (2006) and is described by a probability density function. This PDF of CS gives the distribution of temperature change when the post-industrial equilibrium concentration of $\mathrm{CO}_{2}$ doubles:

$$
\begin{aligned}
& \Delta T_{e q} / \Delta T_{2 x \mathrm{CO}_{2}}=5.35 \cdot \ln \left(C / C_{0}\right) / 5.35 / \ln (2), \text { and thus: } \\
& \Delta T_{e q}=\Delta T_{2 x \mathrm{CO}_{2}} \cdot \ln \left(C / C_{0}\right) / \ln (2)
\end{aligned}
$$

To define the global mean-temperature transient response to changes in the radiative forcing, we consider the climate sensitivity along with the effective vertical ocean heat diffusivity and estimate a time constant $\tau$, defined here as the time needed for the ocean to reach the (1-1/e) of the equilibrium temperature $\Delta T_{e q}$.

Wigley with the help of MAGICC model (Wigley 2003) estimates $\tau$ to depend on the ocean diffusivity $(\mathrm{Kz})$ and the climate sensitivity $\Delta T_{2 x \mathrm{CO}_{2}}$ (Richels et al. 2004):

$$
\begin{aligned}
\tau= & \left(0.04233 \cdot K z^{2}-0.4261 \cdot K z+0.466\right. \\
& \left.+\left(-0.06071 \cdot K z^{2}+0.7277 \cdot K z+0.668 \cdot \Delta T_{2 x \mathrm{CO}_{2}}^{2}\right)\right)
\end{aligned}
$$

This relation is valid for restricted ranges of $\Delta T_{2 x \mathrm{CO}_{2}}$ (i.e., the range $1-7^{\circ} \mathrm{C}$ ) and, therefore if the CS approaches high values, the ocean diffusivity given in Fig. 3 


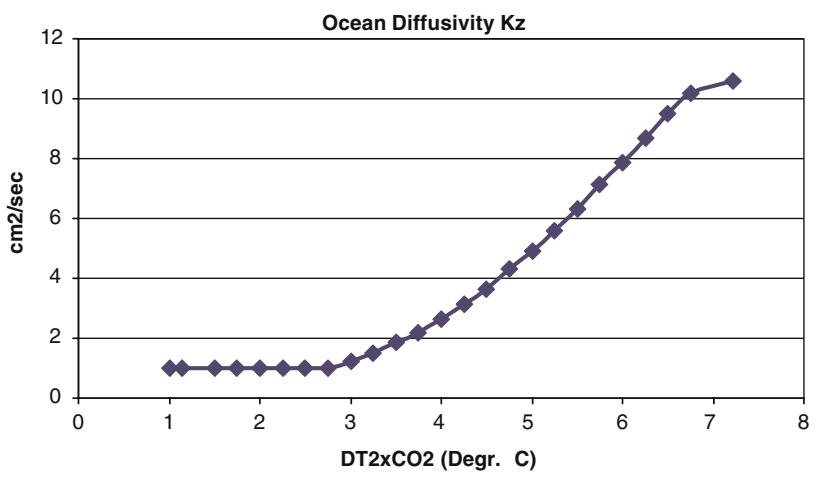

Fig. 3 Ocean diffusivity as function of climate sensitivity adopted in the MCA runs is based primarily on Malte Meinshausen (2006)

is such such that $\tau$ will not exceed 130 years and remains above 1 year for the low ranges of CS.

Constraining methods are used (Knutti et al. 2002) to limit inconsistencies between the ocean energy-balance models and observations, as well as to define the correlation between CS, ocean mixing and sulphate aerosol forcing (Meinshausen 2006). The corresponding maximum likelihood function adopted in the MCA cases shown in Fig. 3 assumes that the climate inertia is high if the climate sensitivity is also high and vice versa (Raper et al. 2001). Fig. 3 derives from Malte Meinshausen (Meinshausen 2006) and is a key relation in the MCA applied in MERGE. As a consequence of this diagram and the Eq. 3 defining $\tau$, at high CS the ocean inertia acts as a buffer that delays transient temperature changes in a way that the threshold of $2^{\circ} \mathrm{C}$ post-industrial can be more easily attained. $^{3}$

Finally, the equilibrium temperature rise reported by the MERGE model because of changes in carbon concentration that accounts for the climate sensitivity is as follows:

$$
\Delta T_{e q}(C)=\frac{\Delta T_{2 x C O_{2}}}{(\text { fbase }+5.35 \cdot \ln (2))} \cdot\left(\text { fbase }+5.35 \cdot \ln \left(C / C_{0}\right)\right)
$$

To this $\mathrm{CO}_{2}$ temperature change component we included the contribution from other GHGs considering their changed concentrations and the induced forcing while the transient temperature change is defined by difference equations that account for $\tau$. The value of fbase $=0.3$ used in the relation above, corrects for the inertia in the ocean response and for the otherwise strong temperature changes induced by the cold start from the year 2000 in the transient temperature estimates of MERGE.

3 There is a possibility that this deterministic representation is not reflecting properly the uncertainty associated with ocean inertia. A recent work at MIT (e.g., Webster et al. 2003) defines a joint probability between $\mathrm{CS}$ and $\mathrm{Kz}$ and aerosols. This kind of joint probability functions could only be considered in a subsequent study where the climate model in MERGE will be fully revised. 


\subsection{Cost/benefit analyses in $\mathrm{MERGE}^{4}$}

When the MERGE model is applied to a cost-benefit analysis, the model accounts for both market and non-market damages (NMD), but attention is focused on NMD. Market damages (MD) are assumed to be proportional to the temperature change. At a temperature rise of $2.5^{\circ} \mathrm{C}, \mathrm{MD}$ would lead to GDP losses of only $0.25 \%$ for the high-income nations (Northern Region), and to losses of $0.50 \%$ for the low-income nations (Southern Region), since smaller amounts of production originate from the agriculture, forestry and fishing sectors for the high-income Northern Region.

NMD include human health, species losses and catastrophic risks such as the shut-down of the thermohaline circulation in the Atlantic Ocean. This kind of loss presents a greater concern to high-income regions than to those with low incomes.

The NMD define welfare loss functions that depend on income and are quadratic in temperature rise. The general principle behind NMD is that all nations are willing to pay to avoid climate change, but poor nations cannot afford to pay a significant part of their income because more severe problems than climate change are faced by the low-income Southern Region.

The "economic loss factor", ELF, applied in MERGE describes the fraction of consumption that remains available to households and government. The non-available part of this income is devoted to combat global warming. Two parameters define the willingness to pay (WTP) to avoid a temperature rise: catt and $h s x$. In high income countries (i.e., at $25 \mathrm{k} \$ /$ year and more), the corresponding hockey-stick reference parameter $h s x$, in MERGE equals unity, and $E L F=0.99$. Generally,

$$
E L F(x)=\left[1-(x / c a t t)^{2}\right]^{h s x}
$$

where $\mathrm{x}$ measures the temperature rise above its level in 2000, while catt is the catastrophic temperature chosen such that the entire regional product is lost at this level of global temperature rise. The hockey-stick parameter is generally defined as follows:

$$
h s x=\ln (1-W T P) / \ln \left(1-(2.5 / c a t t)^{2}\right)
$$

while the WTP for a per capita income $I n$, is given as:

$$
W T P=G D P \operatorname{Los} /(1+100 \cdot \exp (-0.01 / 25 \cdot \operatorname{In}))
$$

with GDPLos being the fraction of GDP citizens are prepared to pay for avoiding a post-2000 temperature change of $W T P \Delta T$.

\footnotetext{
4 This part of the report is based on the original text of A. Manne presented at the Copenhagen Consensus 2004, called "Global Climate Change: An Opponent's Notes" and responds to the presentation of William Cline.
} 
At the reference level of WTP used in MERGE the catt parameter is equal to:

$$
c a t t=W T P \Delta T / \sqrt{G D P L o s}=\frac{2.5^{\circ} \mathrm{C}}{\sqrt{0.02}}=17.6776^{\circ} \mathrm{C} .
$$

We assumed, for the purpose of sensitivity analyses an exceptionally high level of WTP in MERGE as the one presented in Fig. 4. The high level of WTP is calibrated (again) at $1 \%$ of the income spent (i.e., at $25 \mathrm{k} \$ /$ year) but this time to avoid a temperature rise of $1.5^{\circ} \mathrm{C}$ post-2000. In this case of high WTP level, the catastrophic temperature, as given by equation (6C), is catt $=10.61^{\circ} \mathrm{C}$.

The economic loss function ELF is then incorporated into the objective function of MERGE, which again is given by the Negishi-weighted discounted regional utility (e.g., the logarithm of consumption - adjusted for non-market damages) as described below:

$$
\text { Maximand }=\sum_{r} N W_{r} \sum_{t} u d f_{r, t} \cdot \log \left(C_{r, t} \cdot E L F_{r, t}\right)
$$

where: $N W_{r}$ is the Negishi weight assigned to region $\mathrm{r}$ and is determined iteratively so that each region satisfies an inter-temporal foreign-trade budget balance constraint. In this expression $u d f_{r, t}=(1+\rho)^{-t}$ is the utility discount factor assigned to region $\mathrm{r}$ in period $\mathrm{t}$ and $C_{r, t}$, the conventional measure of consumption.

In MERGE the rate of return (ROR) on investments is given by:

$$
R O R=\rho+\theta \cdot g+n
$$

with $\rho$ being the utility discount rate, $\theta$ giving the elasticity of marginal utility, $g$ representing the economic growth rate and $n$ the rate of population growth. The discount rate used in MERGE does not distinguish between the rate of

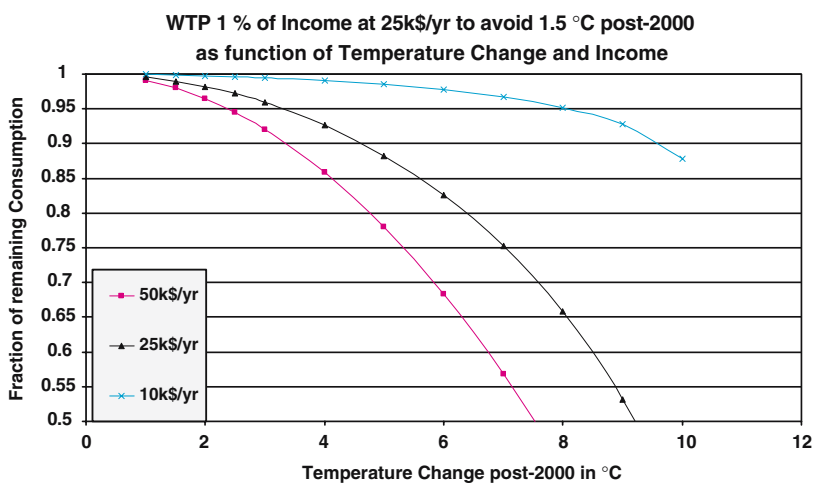

Fig. 4 Willingness-to-pay to avoid climate damages of $1.5^{\circ} \mathrm{C}$ post-2000, given as fraction of consumption per capita and temperature change 
return on consumption and the rate of return on investment. Since the economic growth depends on both region and time, the values of $\rho$ adopted in the utility discount parameter depend also on region and time. Because of the logarithmic utility function employed, the elasticity of marginal utility is set to unity, $\theta=1$. According to Alan Manne, when ROR is defined prescriptively, a utility discount rate of $1 \%$ per year is taken over the planning horizon. Alternatively, under a descriptive approach, the MERGE model assumes that ROR begins at $5 \%$ per year in 2000 and declines linearly to $3 \%$ per annum by the year 2200 , assuming a world that eventually achieves a zero-growth equilibrium. Under a descriptive approach, $\rho$ is constant at $3 \%$ per year. In the MCA adopted in MERGE for this study, these two specifications for the utility discount rate are applied in separate MCA runs.

\section{Equilibrium temperature change}

\subsection{Probability distribution functions for climate sensitivity}

Climate sensitivity (CS) is defined as the expected equilibrium average surface temperature rise that corresponds to a doubling of pre-industrial atmospheric $\mathrm{CO}_{2}$ concentrations. Since the publication of the Third Assessment Report (IPCC TAR 2001), a range of studies have been published defining temperature ranges and/or probability density functions (PDFs) for CS. Figure 5 describes a few such PDFs for CS. Using a standard formula for the radiative forcing, $\Delta \mathrm{F}\left(\mathrm{W} / \mathrm{m}^{2}\right)$, caused by increased $\mathrm{CO}_{2}$ concentrations above pre-industrial levels $\mathrm{C}_{0}$, [i.e., Eq. (1)], an equilibrium temperature rise, $\Delta \mathrm{T}_{\mathrm{eq}}$, can be derived for any $\mathrm{CO}_{2}$ (equivalent) concentration and $\mathrm{CS}$ value, $\Delta \mathrm{T}_{2 \mathrm{xCO}_{2}}$, by applying the following relation:

$$
\Delta T_{e q} / \Delta T_{2 x C O_{2}}=5.35 \cdot \ln \left(C / C_{0}\right) /(5.35 \cdot \ln (2))=\ln \left(C / C_{0}\right) / \ln (2)
$$

The risk $R\left(\Delta T_{\text {lim }}, C, P D F\right)$ of overshooting a certain warming threshold, $\Delta T_{\text {lim }}$, when stabilizing $\mathrm{CO}_{2}$ (equivalent) concentrations at level $\mathrm{C}$ can be calculated in terms of the following integral. (Meinshausen 2006):

$$
R\left(\Delta T_{\lim }, C, P D F\right)=\int_{\Delta T_{\lim }}^{\infty} P D F\left(x\left(\ln (2) / \ln \left(C / C_{0}\right)\right)\right) \cdot d x
$$

with $\operatorname{PDF}\left(\Delta T_{2 x \mathrm{CO}_{2}}\right)$ being the assumed probability density for CS value $\triangle \mathrm{T}_{2 \mathrm{xCO} 2}$.

\footnotetext{
5 The PDFs used in the study have been made available by Malte Meinshausen and are truncated above $10^{\circ} \mathrm{C}$. Furthermore, the conventional IPCC $1.5-4.5^{\circ} \mathrm{C}$ range has been assumed "at hoc due to luck of better knowledge" (Knutti et al. 2006), by Wigley and Raper (2001) as being a 90\% confidence interval for a lognormal distribution while the climate sensitivity PDF by Andronova and Schlesinger (2001) is the one that includes solar and aerosol forcing. Forest et al. (2002)
} 


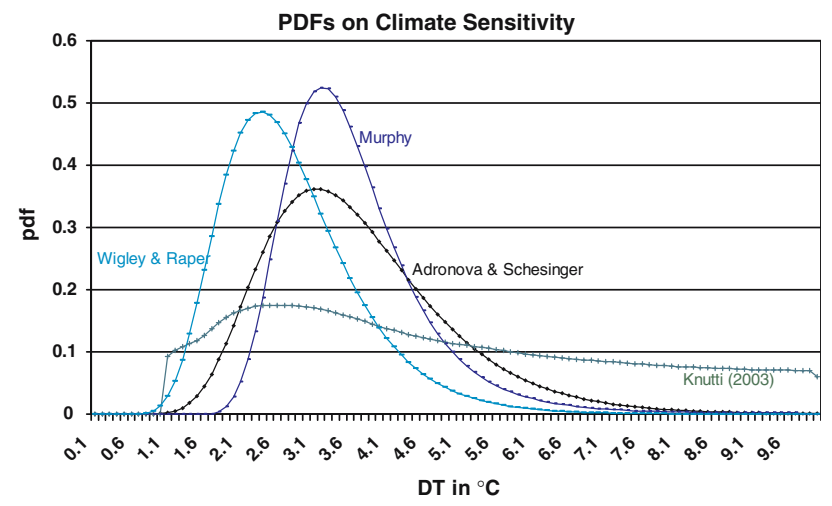

Fig. 5 Probability distribution functions used in the study. ${ }^{5}$ We have selected for MCA two functions: the PDF of Wigley and Raper and the one of the Knutti et al. The first one assumes a median of $2.6^{\circ} \mathrm{C}$ and a $90 \%$ confidence level to be confined between 1.5 and $4.5^{\circ} \mathrm{C}$ while the second gives significantly higher mean and variance

\subsection{Long-term equilibrium temperature change}

Based on Eq. (9) and a given PDF, the distribution of temperature change at different stabilization targets of $\mathrm{CO} 2$ equivalent ${ }^{6}$ concentrations have been estimated and displayed in Figs. 6 and 7 for the PDF of Wigley and this of Knutti, respectively.

Based on Fig. 7 it is concluded that to achieve a maximum median temperature change of $2^{\circ} \mathrm{C}$ under post-industrial conditions, the long-term $\mathrm{CO}_{2}$-eq concentration should remain at (or below) 400 ppmv under the PDF used by Knutti et al. (Fig. 7). On the contrary, under the PDF of Wigley and Raper (Fig. 6) an equivalent concentration of 500 ppmv is almost sufficient to obtain a maximum median temperature of $2^{\circ} \mathrm{C}$ post-industrial.

Figures 8 and 9 respectively define the risk of overshooting the EU target of $2^{\circ} \mathrm{C}$ and the DAI target $2.85^{\circ} \mathrm{C}$ for post-2000 conditions (i.e., the so-called Dangerous Anthropogenic Interference) temperature threshold, as defined by Mastrandrea and Schneider (2004). Following the PDF of Knutti et al. for CS, the median of carbon equivalent concentrations must be stabilized below 400 ppmv to satisfy the EU target, whereas the median concentration is around 475 ppmv following PDF adopted by Wigley and Raper.

The $50 \%$ percentile (median) for a temperature change above $2.85^{\circ} \mathrm{C}$ (post2000) intercepts the Knutti et al. PDF at 490 ppm-eq., while this median point

estimates CS with expert and uniform a priori distributions; other observationally based estimate is the one by Gregory et al. (2002); the uniform prior estimate by Knutti et al. (2003); and a recent estimate based on a 53 ensemble of a large GCM, HadAM3 (Murphy et al. 2004). We focus our analyses to the PDFs of Wigley and Raper and to this of Knutti et al. (2003). The truncation for the $\mathrm{CDF}$ of Knutti et al. above $10^{\circ} \mathrm{C}$ and below $1^{\circ} \mathrm{C}$ introduces some counterbalancing bias.

6 The $\mathrm{CO}_{2}$ equivalent $\left(\mathrm{CO}_{2}\right.$-eq) concentration produces the same radiative forcing as caused by $\mathrm{CO}_{2}$ and all other greenhouse gases. 
Post-industrial long term temperature change based on Wigley and Raper

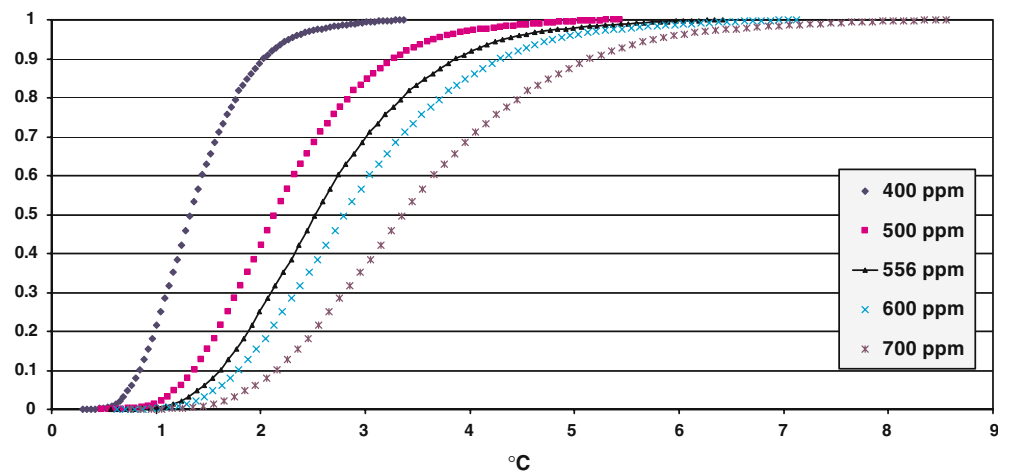

Fig. 6 Post-industrial temperature rise at different $\mathrm{CO}_{2}$-eq concentrations following the PDF of Wigley and Raper on climate sensitivity

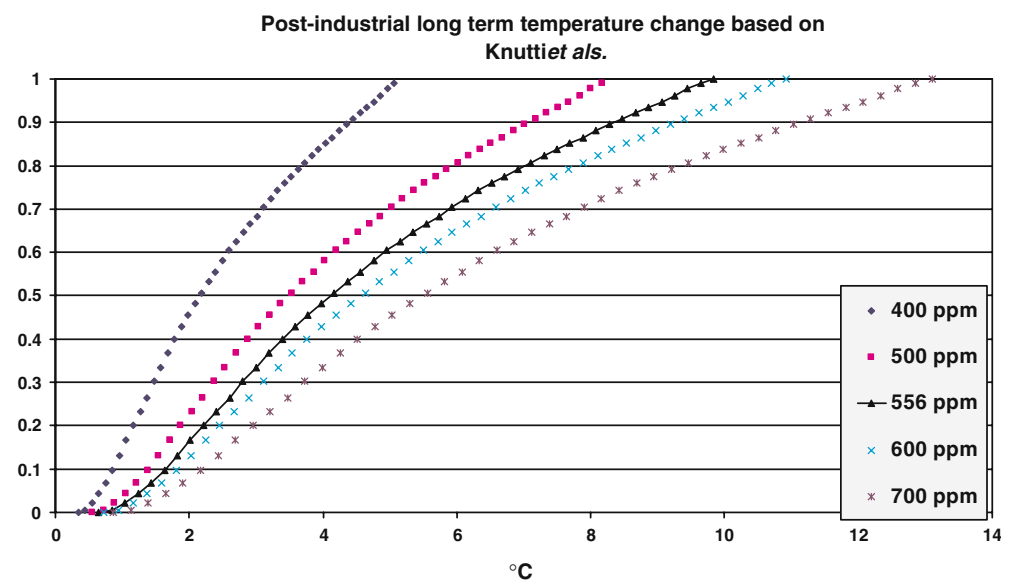

Fig. 7 Post-industrial temperature rise for different $\mathrm{CO}_{2}$-eq. concentrations following the PDF of Knutti et al. on climate sensitivity

for the PDF of Wigley and Raper occurs at 700 ppm-eq., which corresponds approximately to $\mathrm{CO}_{2}$ concentrations of 440 and 650 ppmv, respectively.

\subsection{Transient temperature change}

Based on the previous calculation of equilibrium temperature change (Sect. 3.2) and adopting the difference and recursive equations as applied in MERGE, the transient temperature change can be determined. For that we perform simple MC estimates for different CS values to define the median, mean and the confidence levels of the transient temperature rise for different years into the future. This work assumes the same evaluation of the ocean diffusivity and the ocean response time $\tau$, as described in the Sect. 2.4 and scenarios with constant GHG 


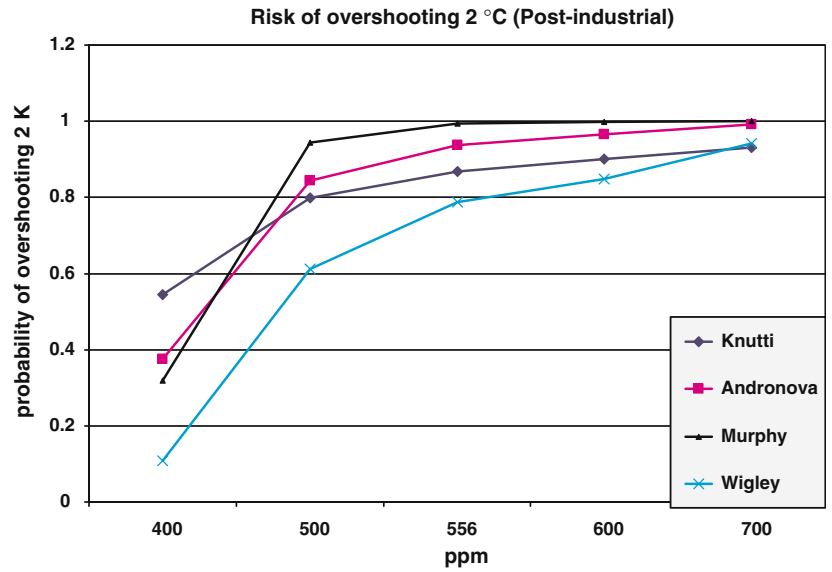

Fig. 8 The long term risk of overshooting $2^{\circ} \mathrm{C}$ post-industrial at a $\mathrm{CO}_{2}$-eq concentration level of $400 \mathrm{ppmv}$ is $10 \%$ under Wigley and $55 \%$ under Knutti et al. and becomes almost $100 \%$ at $556 \mathrm{ppmv}$ under Murphy and 78\% under Wigley and Raper

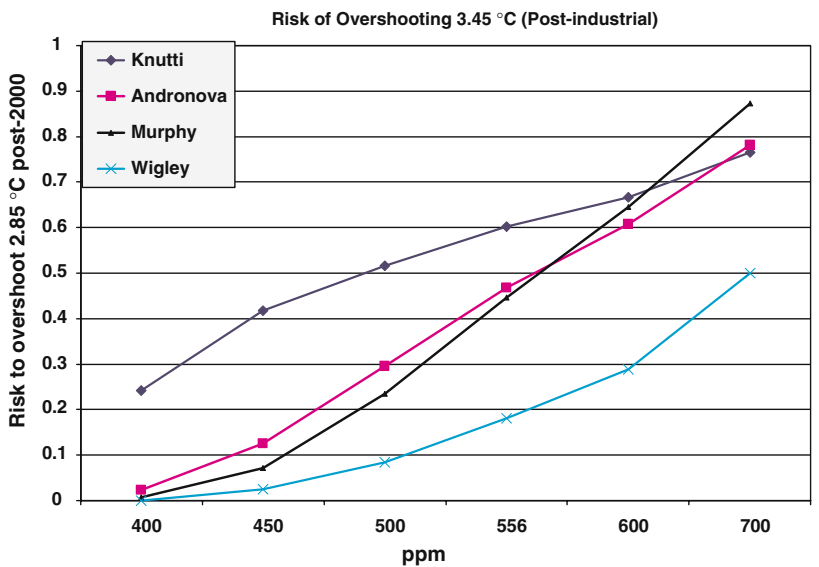

Fig. 9 The median of long term risk (i.e., at $50 \%$ risk) to overshoot $3.45^{\circ} \mathrm{C}$ post-industrial (or $2.85^{\circ} \mathrm{C}$ post-2000) is violated above $490 \mathrm{ppm}$ under Knutti and above $700 \mathrm{ppm}$ under Wigley and Raper

concentrations. Simplicity represents the main attractiveness of this approach in that all the complexity of socioeconomic and cost-benefit analyses done in MERGE can be by-passed, as we calculate directly the transient temperature changes for fixed concentrations. The equilibrium temperature change $\Delta T(C)_{e q, t}$ and the recursive formula ${ }^{7}$ for the transient temperature change

\footnotetext{
7 The difference equation 12, second term, describes how the transient temperature change $\Delta T R$ decays each year by the fraction $1-1 / \tau$, due to heat transfer to the deeper levels of the ocean, while the first part explains how the transient temperature is approaching the long term equilibrium temperature change (i.e., the mean in two subsequent decades) each decade, and it is fully based on the formulation in MERGE5.1.
} 
Table 2 Mean of post-industrial temperature change in ${ }^{\circ} \mathrm{C}$, for different $\mathrm{CO}_{2}$-eq. concentrations, following the PDF of Knutti et al.

\begin{tabular}{lllll}
\hline & $400 \mathrm{ppm}$ & $450 \mathrm{ppm}$ & $500 \mathrm{ppm}$ & $556 \mathrm{ppm}$ \\
\hline 2040 & 0.738 & 0.977 & 1.19 & 1.406 \\
2050 & 0.885 & 1.171 & 1.427 & 1.685 \\
2080 & 1.226 & 1.622 & 1.977 & 2.335 \\
2100 & 1.398 & 1.851 & 2.256 & 2.664 \\
2120 & 1.541 & 2.04 & 2.486 & 2.936 \\
2150 & 1.713 & 2.267 & 2.763 & 3.263 \\
\hline
\end{tabular}

Table 3 Post-industrial long term equilibrium temperature change and statistics in ${ }^{\circ} \mathrm{C}$ for different $\mathrm{CO}_{2}$-eq. concentrations, following the PDF of Knutti et al.

\begin{tabular}{lllll}
\hline & $400 \mathrm{ppm}$ & $450 \mathrm{ppm}$ & $500 \mathrm{ppm}$ & $556 \mathrm{ppm}$ \\
\hline 90\% confidence level & $0.502-4.674$ & $0.684-6.187$ & $0.774-7.54$ & $0.86-8.904$ \\
Median & 1.963 & 2.599 & 3.167 & 3.74 \\
Mean & 2.365 & 3.13 & 3.815 & 4.505 \\
Standard deviation & 1.255 & 1.661 & 2.025 & 2.391 \\
\hline
\end{tabular}

$\Delta T R_{t+1}$ at a concentration $C_{t}$ are defined as follows:

$$
\begin{aligned}
\Delta T(C)_{e q, t}= & \Delta T_{2 x C O_{2}} \cdot \ln \left(C_{t} / C_{0}\right) / \ln (2) \\
\Delta T R_{t+1}= & 0.5 \cdot\left(\Delta T(C)_{e q, t+1}+\Delta T(C)_{e q, t}\right) \cdot\left(1-(1-1 / \tau)^{10}\right) \\
& +\Delta T R_{t} \cdot(1-1 / \tau)^{10}
\end{aligned}
$$

All that is needed is to sample values of $\Delta T_{2 x \mathrm{CO}_{2}}$ following a given PDF and then to define the statistics for the median the mean and the confidence levels of the transient temperature change for different years. Results of this computation are shown in Tables 2 and 3.

For high CS values the value of ocean diffusivity parameter is also high, and the time required reaching equilibrium temperatures could be more than 100 years. Hence, even for the PDF of Knutti et al., the reported mean actual temperature change until the end of the twenty first century is lower than the median of PDF on CS (i.e., the mean shown in Table 2, is $2.664^{\circ} \mathrm{C}$ while the equilibrium and long term median shown in Table 3 for the PDF of Knutti et al. is $3.74^{\circ} \mathrm{C}$ ). The EU target, therefore, becomes an easier target to satisfy. In the following sections, the MERGE model is used to generate different scenarios on GHGs concentrations that reach values above doubling of the pre-industrial levels, based on CBA equilibrium solution in a MC framework. The way in which the transient temperature change evolves over time under different policy profiles reducing temperature change is then shown and discussed. 


\section{Monte Carlo results for the baseline}

The population, GWP and energy indicators for the baseline cases have been discussed in Sect. 2.3. The baseline temperature change by the year 2150 remains well below $6^{\circ} \mathrm{C}$ for the PDF of Wigley (Fig. 10) and below $8^{\circ} \mathrm{C}$ (post-industrial) for the PDF of Knutti et al. (Fig. 12). Also, long-term atmospheric carbon concentrations approach a maximum level of $\sim 1000$ ppmv. These concentration levels is a consequence of the depletion of oil and gas resources that enhance the use of coal while eventually advanced fossil and/or carbon-free technologies become competitive in future markets, particularly since the latter technologies are assumed to exhibit high learning rates.

As expected, in the absence of policies designed to mitigate global warming, only a small fraction of baseline cases $\sim 1-2 \%$ attain a temperature rise below $2^{\circ} \mathrm{C}$. Figure 11 indicates that the median temperature change by the year 2100 is above $3.3^{\circ} \mathrm{C}$ (post-industrial) for the PDF of Wigley while in the year 2150 in the case of Knutti we could have very high temperature increases (Fig. 12).

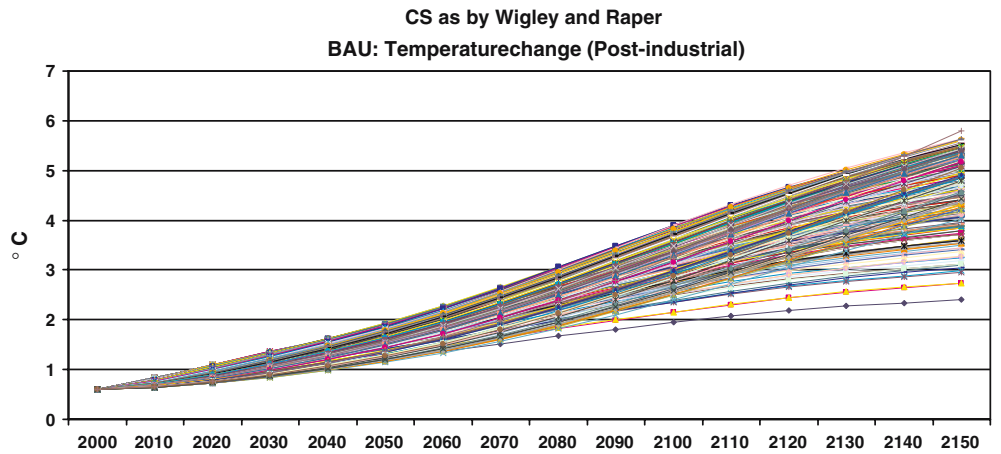

Fig. 10 Results of the baseline following the PDF of Wigley and Raper for climate sensitivity. Each graph shown here represents the temperature change trajectories generated by a MCA run. Temperature change is reaching levels between 2.4 and $5.7^{\circ} \mathrm{C}$ in 2150 as carbon concentrations reach maximum levels of $1000 \mathrm{ppmv}$

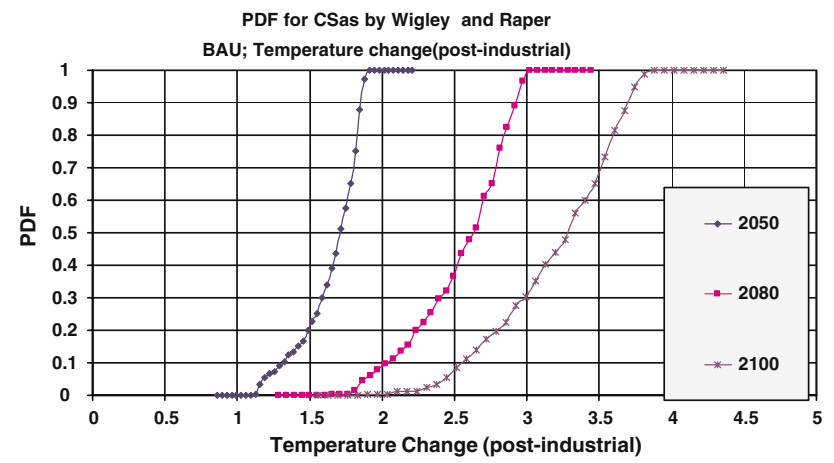

Fig. 11 In the baseline case almost $99 \%$ of cases are above $2{ }^{\circ} \mathrm{C}$ post-industrial in the year 2100 


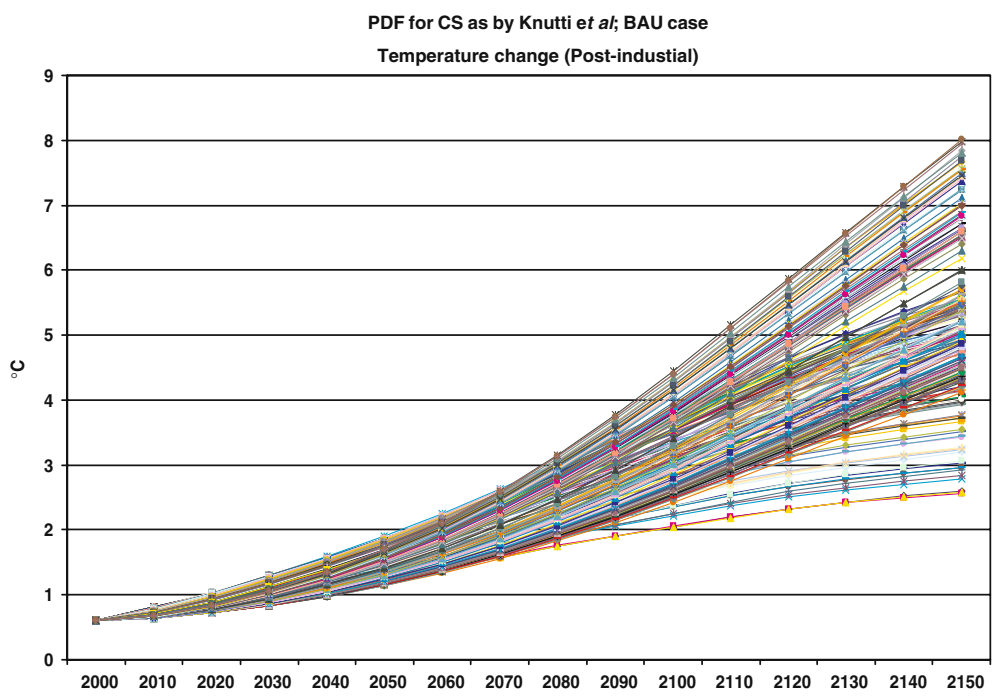

Fig. 12 Results of the baseline case following the PDF of Knutti et al. (2003) for CS. Now temperature changes are much higher than in the case of Wigley

\section{Monte Carlo results for the CBA cases}

\subsection{General description of results}

Figures 13, 14, 15, 16, 17, 18 and 19 describe the behaviour of key socioeconomic and energy-system indicators within a cost/benefit framework, where the market and non-market damages are taken into account when allocating the use of the economic output and when reducing household consumption to cope with climate change. Under such circumstances, the environmental situation in terms of temperature change improves. Two different WTP levels are assumed, two different discount rates are used, and separate MCA runs are performed for each combination of these assumptions. As income increases in the second part of the twenty first century the WTP increases and, therefore, the temperature change is moderate.

Under the PDF for the CS of Wigley and Raper and for the reference WTP, the temperature change by the year 2100 remains between 1.5 and $2.5^{\circ} \mathrm{C}$, with a median of $2.08^{\circ} \mathrm{C}$ (post-industrial), where the target threshold of $2^{\circ} \mathrm{C}$ (postindustrial) is satisfied by around $40 \%$ of the cases considered (Fig. 14). The mean carbon value remains below $155 \$ / \mathrm{tC}$ in the twenty first century and reach a maximum at $260 \$ / \mathrm{tC}$ in the twenty second century. When the utility discount rate is reduced to $1 \%$ per annum, the median is again below $2{ }^{\circ} \mathrm{C}$ (Fig. 15).

Under Knutti et al. PDF and for high levels of the WTP, the temperature change remains between 1.4 and $2.4^{\circ} \mathrm{C}$ and the postulated threshold of $2^{\circ} \mathrm{C}$ is well satisfied by almost $70 \%$ of the cases analyzed (Fig. 16). The mean carbon value is very high around $600 \$ / \mathrm{tC}$ in the twenty first century and increases in 


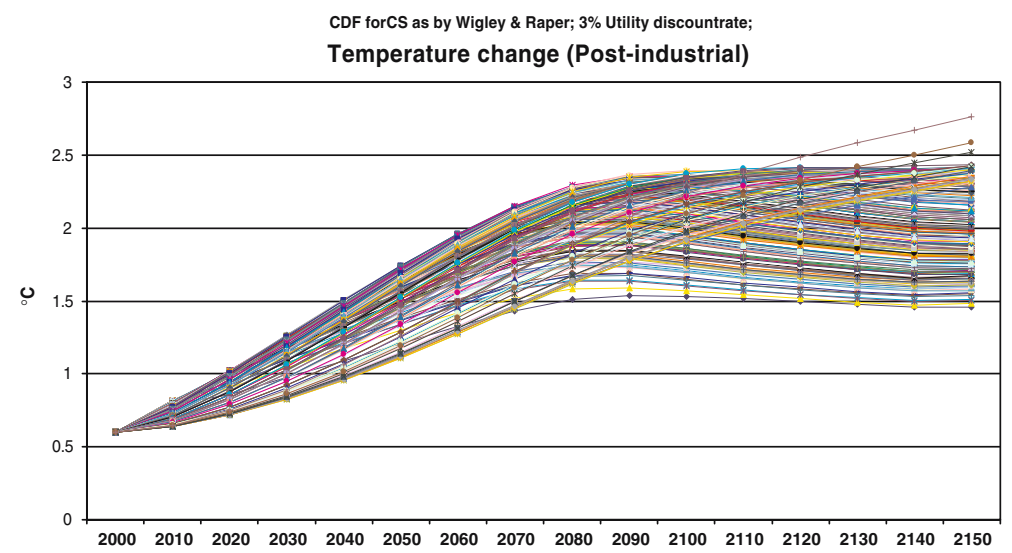

Fig. 13 The temperature change is sufficiently controlled if the Reference WTP is assumed and a descriptive utility discount rate of $3 \%$ is used in the CBA cases

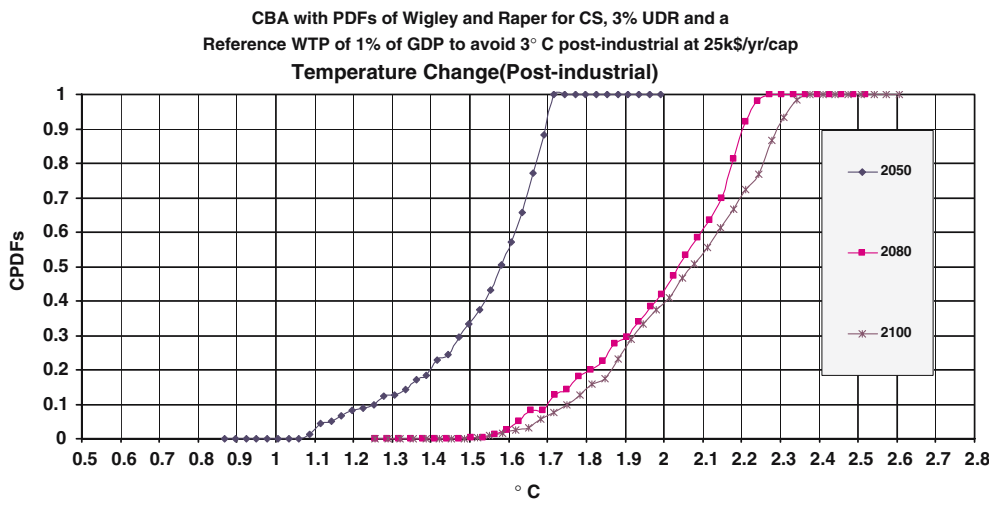

Fig. 14 The median temperature change in 2100 is $2.08^{\circ} \mathrm{C}$ (post-industrial) at $3 \%$ UDR

CBA with PDFs of Wigley and Raper for CS, $1 \%$ UDR and a Reference WTP of $1 \%$ of GDP to avoid $3^{\circ} \mathrm{C}$ post-industrial at $25 \mathrm{k} \$ / \mathrm{yr} / \mathrm{cap}$

Temperature Change (Post-industrial)

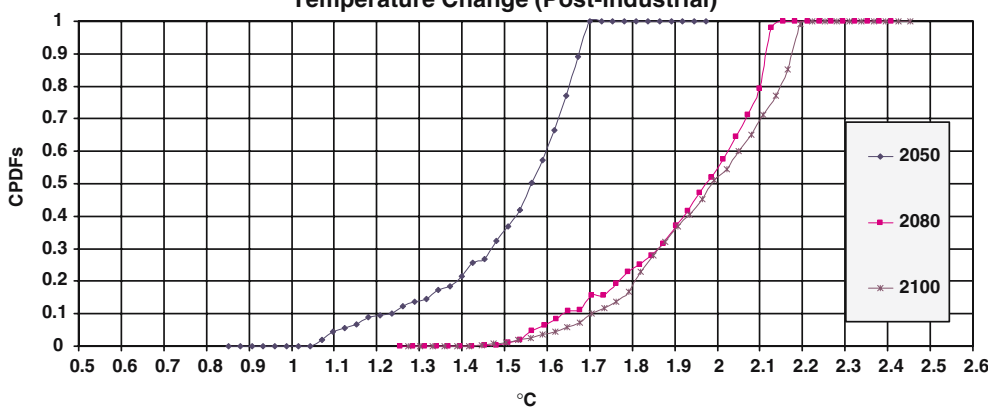

Fig. 15 The median temperature change in 2100 is well below $2^{\circ} \mathrm{C}$ post-industrial at $1 \%$ UDR 


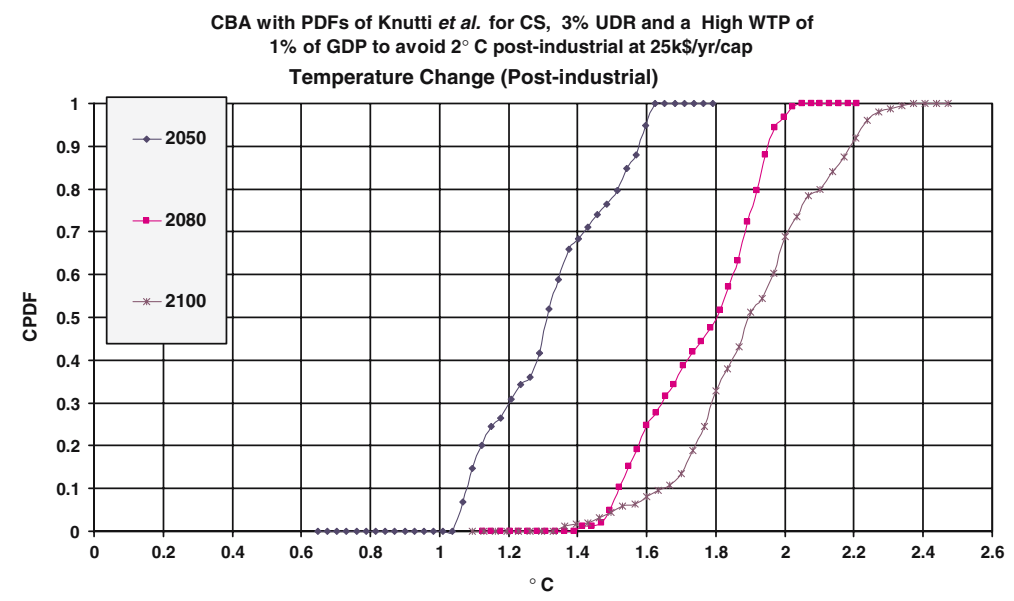

Fig. 16 The median temperature change in 2100 remains below $2^{\circ} \mathrm{C}$ post-industrial when a high WTP is postulated

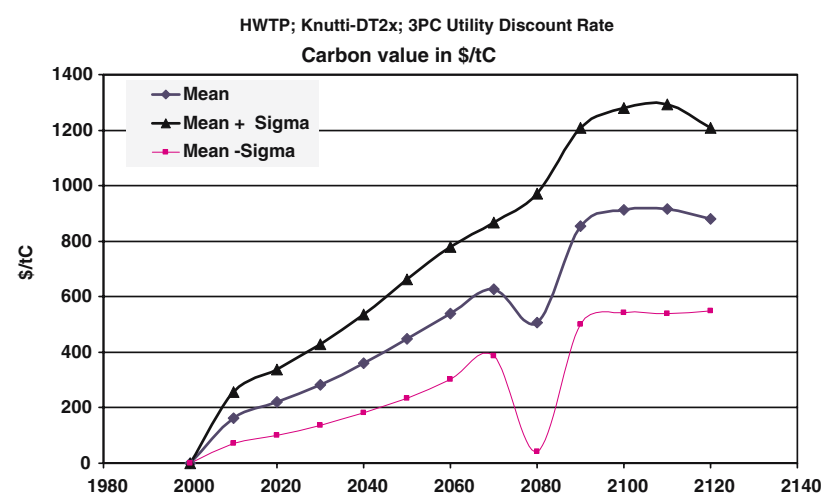

Fig. 17 The carbon price trajectory shown above is typical for cases when upper bounded technologies with endogenous technological learning appear in the markets and the energy use increases. The first local minimum around 2080 is due to LBD cost reductions for the marginal technology. After the upper bound on the availability of this technology is reached, the marginal control cost increases again up to the point that LBD of a new technology is active again

the twenty second century to a maximum of $900 \$ / \mathrm{tC}$ (Fig. 17) because of the low emission trajectories induced by the high cost of NMD. As a consequence, the consumption loss varies from 0.5 to $5 \%$ of the GWP for the cases analyzed (Fig. 18).

\subsection{The portfolio of technologies for the target $2{ }^{\circ} \mathrm{C}$ (post-industrial) average global temperature rise}

The main consequence of the EU policy target of a maximum $2{ }^{\circ} \mathrm{C}$ post-industrial temperature rise is the need for a significant restructuring of the present 
HWTP; Knutti-DT2x; 3\% Utility Discount Rate;

NM-Damages as \% of Consumption

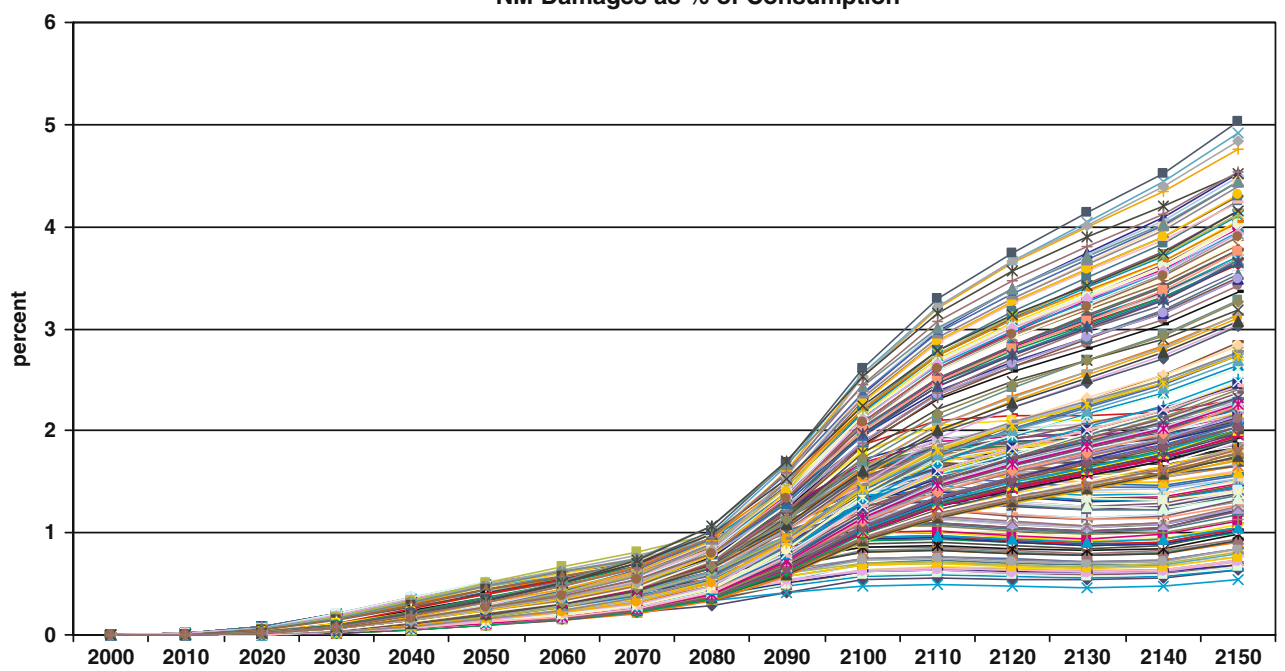

Fig. 18 The damages vary significantly between $0.5 \%$ of consumptions and $5 \%$ at high temperature change levels, when a very high WTP is assumed

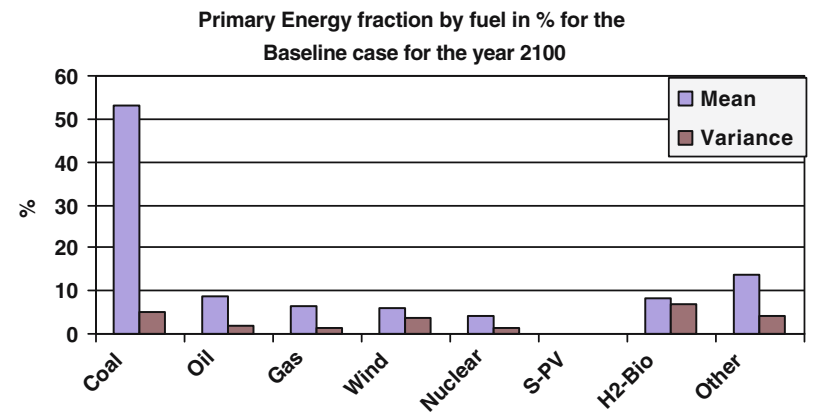

Primary Energy fraction by fuel in $\%$ for $\mathbf{2 1 0 0}$

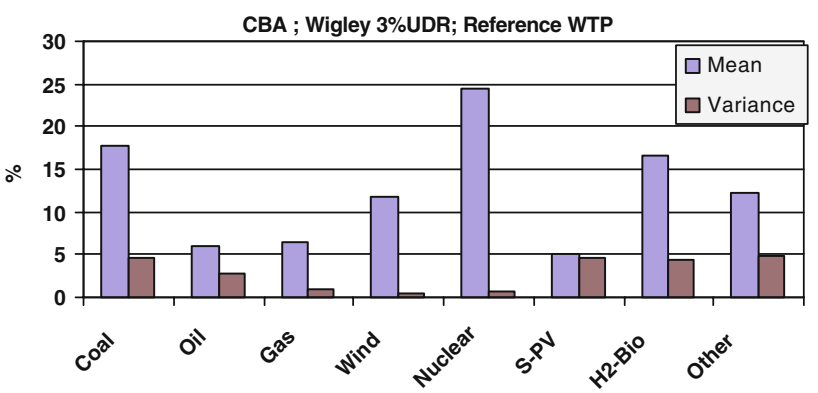

Fig. 19 The primary energy use by fuel in percent for 2100 (i.e., mean and variance) for the Baseline and a CBA case 
global energy system, which presently relies on fossil fuels, towards a more sustainable portfolio of technological options. The restructuring refers to the primary-energy production by fossil and non-fossil fuels for the cases where a high WTP to avoid serious climate change damages has been assumed.

The first conclusion is that oil and gas resources are depleted and their use is reduced to a small fraction of the primary-energy mix. Secondly, technologies like wind, new nuclear and solar PV penetrate the markets and substitute for fossil fuels in the electricity-generation sector. Thirdly, hydrogen production based on carbon sources using carbon capture and sequestration (CCS) contributes significantly to the future energy mix while simultaneously stabilizing atmospheric carbon concentrations. Fourthly, a massive introduction of commercial biomass as an emerging industry to substitute for oil and gas is necessary for either the production of hydrogen or for the generation of bio-fuels.

Lastly, no single technology can be characterized as a "magic bullet" that can provide a solution to all energy and environmental issues facing mankind. This last finding is especially true for conditions where the EU policy goal of $2^{\circ} \mathrm{C}$ (post-industrial) global average temperature rise is aimed for in a world where oil and gas resources are depleted under conditions where economic development reaches the high levels assumed in this study. Commercial biomass then becomes a candidate technology that approaches the stature of a "silver bullet", but, on the other hand, carbon-free systems like nuclear, wind and solar PV together with coal combined with CCS contribute by another $60-70 \%$ of the primary energy consumption with the biomass generated hydrogen contributing to $15 \%$ of the primary energy production (Fig. 19).

The model identifies coal to be the most important fuel contributing to the primary energy supply in the year 2100 , for the Baseline case, as there is no policy foreseen to control carbon emissions. Otherwise, in a CBA case that balances costs and benefits of carbon emission control, nuclear, coal with CCS, $\mathrm{H}_{2}$ produced from bio-fuels, and wind share the most important parts of energy supply. A significant variance for Solar-PV, $\mathrm{H}_{2}$-biofuels and CCS systems is presented in the diagrams, induced by the random behavior of endogenous learning by doing rates.

\section{Conclusions}

The scope of this study is to assess the effectiveness of climate-change mitigation policies in restricting global average surface temperature rise to below some critical thresholds (e.g., $2^{\circ} \mathrm{C}$ above the pre-industrial levels). This study applies Monte Carlo Analyses in conjunction with a range of PDFs to define the probability of exceeding these specified thresholds. We simulate different levels of willingness-to-pay that enable for the global socio-economic and energy system to remain below these limits, and we assess the associated cost to the economy of achieving these temperature-rise targets together with the technological change needed to restructure the present energy sector. 
Despite the model difficulties and simplifications, especially in the evaluation of the transient temperature change, this probabilistic framework presents an alternative method for conceptualizing climate-change policy decisions (Mastrandrea and Schneider 2004). The messages derived from these analyses are significant:

- The policy target of $2^{\circ} \mathrm{C}$ (post-industrial) by the end of 2100 is arbitrary in terms of the threshold level chosen and the time horizon explored, while the success of that policy is low if PDFs for Climate Sensitivity like the one suggested by Knutti et al. prevails.

- The policy target of a temperature change of $2^{\circ} \mathrm{C}$ above pre-industrial levels represents a difficult target for the PDF and WTP parameters assumed. Either the world-wide level of WTP must be significantly improved relative to present-day attitudes (the need for increased WTP refers to the whole world and not only to Europe), or we have to adopt moderate temperature threshold targets and adapt to the associated environmental impacts.

- A restructuring of the global energy system towards a more sustainable and carbon- free system is technically feasible, but expensive, and requires a massive mobilization of resources and a very strong societal commitment to be materialized. The results obtained from this study are optimistic, since they are based on an assumed potential of $400 \mathrm{EJ} / \mathrm{year}$ for bio-fuels and a successful technology development and implementation (not to mention advances in CCS technologies assumed). Additionally, full cooperation across all world regions in terms of devoting resources to reduce global warming, as well as a global acceptance of the induced carbon tax, has been assumed,.

- The "optimal" tax trajectory needed to avoid a given risk of overshooting critical temperature limits strongly depends on the applied PDF describing the CS parameter, the portfolio of technological options to be made available in the future and the utility discount rate.

- The reference WTP used in MERGE is quadratic in temperature change and corresponds to the spending of $1 \%$ of regional GDP (for an income of $25 \mathrm{k} \$$ capita) to avoid a temperature change of $2.5^{\circ} \mathrm{C}$ (post-2000). Applying the PDF suggested by Wigley and Raper to the CS parameter, we estimate carbon concentrations that become high over time but are affordable. The corresponding median temperature rise is $2.08^{\circ} \mathrm{C}$ (post-industrial) in 2100 (i.e., in a CBA framework and a descriptive utility discount rate of $3 \%$ per annum). The mean value of carbon taxes remain below $\$ 155$ per ton of carbon in the twenty first century, while the amount of consumption losses amounts to $\sim 0.7$ percent (compared to consumption in the baseline). The median temperature change is reduced to $1.76^{\circ} \mathrm{C}$ when a prescriptive discount rate of $1 \%$ is adopted.

- When the PDF suggested by Knutti et al. is applied, which is characterized by higher CS levels, more drastic restrictions on the GHG emissions and a high WTP are required, which is well above the reference assumptions of MERGE. For a 3\% utility discount rate and the reference WTP, the 
median remains above $2^{\circ} \mathrm{C}$, whereas for high WTP, $70 \%$ of the cases have a temperature rise below $2^{\circ} \mathrm{C}$ (post-industrial). The Non-Market Damages in this case are between $0.5 \%$, and a maximum of $5 \%$ at high climate sensitivity ranges. The carbon value assumes two peaks over time: one around $600 \$ \mathrm{t} / \mathrm{C}$ in 2080 and another at $900 \$ / \mathrm{tC}$ in 2130.

- It is found that there is no one single technology that allows this ambitious policy target to be satisfied. Technologies like energy conservation, efficient power generation systems based on coal and gas with CCS, nuclear energy, wind, solar PV, biomass and other renewables are found to penetrate into future energy markets for both global regions examined. Perhaps the most significant technology at this low temperature threshold is the massive introduction of biomass plantations to provide the raw materials needed for hydrogen or bio-fuel production associated with CCS that in principle provides a natural route for removing carbon from the atmosphere.

- Although some natural scientist (Meinshausen 2006), convey optimistic messages about the ability to avoid average global temperature changes above $2^{\circ} \mathrm{C}$ (post-industrial), the efforts and coordination associated to that mitigation target and the cost penalty related with these policies is so high that it becomes difficult to remain optimistic.

- No objective and quantitative specification of what "dangerous anthropogenic interference with the climate" exactly means is available, since this description is based largely on value judgments. It would be helpful for decision making to define more precise temperature thresholds that could lead to irreversible climate changes. Priority should be given to the assessment of key changes like the Greenland and Artic ice melting (Oppenheimer and Alley 2004), the thermohaline circulation and the release of methane hydrates (Schellnhuber 2006). Science must also reduce the uncertainty on targeted CS values if policy decisions other than the "no-regrets" varieties are to be taken and, most importantly, if an extension of the Kyoto protocol is to be achieved.

- Lastly, the estimated CPDFs on temperature change as function of policies analyzed herein is helpful in defining the risk associated with alternative temperature thresholds.

Acknowledgment The financial support of the Swiss NCCR-Climate (grant from the Swiss National Science Foundation) and the EU-ADAM project is highly appreciated.

I am indebted to Malte Meinshausen for making available the probability density functions on climate sensitivity and for an early review of the manuscript and to Robert Krakowski for a critical review of the manuscript and the editorial improvements. I will like to also thank the two anonymous reviewers and the editor for the constructive remarks concerning the article.

The paper is devoted to the memory of Alan Manne who had a strong influence on my research activities in the last decade.

\section{References}

Andronova NG, Schlesinger ME (2001) Objective estimation of the probability density function for climate sensitivity. J Geophys Res Atmos 106:22605-22611 
Azar C, Lindgren K, Larson E, Möllersten K (2006) Carbon capture and storage from fossil fuels and biomass - Costs and potential role in stabilizing the atmosphere. Clim Change 74:47-79

Energy Information Administration (EIA) (2003) at http://www.eia.doe.gov/oiaf/archive/ieo03/ index.html

Fankhauser S (1994) The social cost of GHG emissions: an expected value approach. Energy J 15/2:157-184

Forest CE, Stone PH, Sokolov A, Allen MR, Webster MD (2002) Quantifying uncertainties in climate system properties with the use of recent climate observations. Science 295:113-117

Fragnière E, Haurie A (1996) MARKAL-geneva: a model to assess energy-environment choices for a Swiss Canton. In: Carraro C, Haurie A (eds) Operations research and environmental management. Kluwer Academic Books, Dordrecht

Gregory JM, Stouffer RJ, Raper SCB, Stott PA, Rayner NA (2002) An observationally based estimate of the climate sensitivity. J Clim 15:3117-3121

Hare B, Meinshausen M (2004) How much warming are we committed to and how much can be avoided?' PIK Report. Potsdam, Potsdam Institute for Climate Impact Research: 49. No. 93 http://www.pik-potsdam.de/publications/pik_reports

IPCC, Third Assessment Report, Climate Change 2001.Cambridge Universtity Press, Cambridge, United Kingdom, at http://www.grida.no/climate/ipcc_tar/

Knutti R, Stocker TF, Joos F, Plattner G-K (2003) Probabilistic climate change projections using neural networks. Clim Dyn 21:257-272

Knutti R, Stocker TF, Joos F, Plattner G-K (2002) Constraints on radiative forcing and future climate change from observations and climate model ensembles. Nature 416:719-723

Knutti R, Meehl AG, Allen RM, Stainforth AD (2006) Constraining climate sensitivity from the seasonal cycle in surface temperature. J Clim (in Press)

Manne A, Mendelsohn R, Richels R (1995) MERGE: a model for evaluating regional and global effects of GHG reduction policies. Energy Policy 23(1):17-34

Kypreos S (2005) Modeling experience curves in MERGE (model for evaluating regional and global effects). Energy 30(14):2721-2737

Manne AS, Richels RG (1999) The Kyoto Protocol: a cost-effective strategy for meeting environmental objectives?. Energy J Special Issue on the Costs of the Kyoto Protocol: A Multi-Model Evaluation, 1-24

Manne AS, Barreto L (2004) Learn-by-doing and carbon dioxide abatement. Energy Econ 26(4):621-633

Mastrandrea MD, Schneider SH (2004) Probabilistic integrated assessment of "Dangerous" climate change. Science 304:571-575

Meinshausen M (2006) What does a $2{ }^{\circ} \mathrm{C}$ target mean for greenhouse gas concentrations? A brief analysis based on multi-gas emission pathways and several climate sensitivity uncertainly estimates. In: Schellnhuber HJ, Cramer W, Nakicenovic N, Wigley T, Yohe G (eds) Avoiding dangerous climate change. Cambridge University Press, ISBN-10: 0521864712

Murphy JM, Sexton DMH, Barnett DN, Jones GS, Webb MJ, Collins M, Stainforth DA (2004) Quantification of modelling uncertainties in a large ensemble of climate change simulations. Nature 430:768-772

Nakicenovic N, Swart R (eds) (2000) IPCC special report on emissions scenarios. Cambridge University Press, Cambridge, United Kingdom, p 612

Nordhaus W (1993) Rolling the DICE: an optimal transition path for controlling GHG's. Resour Energy Econ 15/1:27-50

Nordhaus DW (1999) The economic impacts of abrupt climatic change. Paper prepared for a meeting on abrupt climate change: the role of oceans, atmosphere, and the polar regions. National Research Council, January 22, 1999

Negishi T (1972) General equilibrium theory and international trade. North-Holland Publishing Company, Amsterdam

Oppenheimer M, Alley RB (2004) The West Antarctic ice sheet and long term climate policy. Clim Change 64:1-10

Peck SC, Teisberg TJ (1995) Optimal $\mathrm{CO}_{2}$ control policy with stochastic losses from temperature rise. Clim change 31/1:19-34

Raper SCB, Gregory JM, Stouffer RJ (2001) The role of climate senstivity and ocean heat uptake on AOGCM transient temperature response. J Clim 15:124-130 
Peterson S (2006) Uncertainty and economic analysis of climate change: a survey of approaches and findings. Environ Model Assess 11(1):1-17

Richels R, Manne A, Wigley T (2004) Moving beyond concentration: the chanllenge of limiting temperature change. Working Paper 04-11, April 2004, Joint Center, AEI-Brookings Center for Regulatory Studies

Schellnhuber HJ, Cramer W, Nakicenovic N, Wigley T, Yohe G (eds) (2006). Avoiding dangerous climate change, University Press Cambridge, ISBN-10: 0521864712

Seebregts AT et al. (2000) Endogenous learning of technology clusters in a MARKAL model of the Western European energy system. IJGEI, vol. 14, No. 1-4, pp 289-319

Smith JB, Schellnhuber H-J, Mirza MMQ, Fankhauser S, Leemans R, Erda L, Ogallo L, Pittock B, Richels R, Rosenzweig C et al. (2001) In climate change 2001: impacts, adaptation, and vulnerability: contribution of working group II to the Third assessment report of the intergovernmental panel on climate change. In: McCarthy JJ, Canziani OF, Leary NA, Dokken DJ, White KS Cambridge University Press, Cambridge, UK, pp 913-967

Tol RSJ, Yohe GW (2006) Of dangerous climate change and dangerous emission reduction. In avoiding dangerous climate change Edited by Hans Joachim Schellnhuber, Wolfgang Cramer, Nebojsa Nakicenovic, Tom Wigley, Gary Yohe, Cambridge University Press, ISBN-10: 0521864712

Tol RSJ (2003) Is the uncertainty about climate change too large for expected cost-benefit analysis? Clim Change 56(3):265-289

Webster $\mathrm{M}$ et al (2003) Uncertainty analysis of climate change and policy response. Clim Change 61(3):295-320

Wigley TML, Raper SCB (2001) Interpretation of high projections for global-mean warming. Science 293:451-454

Wigley TML (2003) MAGICC/SCENGEN 4.1: technical manual. Boulder, Colorado, UCARClimate and Global Dynamics Division. available at http://www.cgd.ucar.edu/cas/wigley/magicc/index.html

WBGU (German Advisory Council on Global Change) (2003) Climate protection strategies for the 21st Century: Kyoto and beyond, Special Report available at http://www.wbgu.de/ wbgu_sn2003_engl.pdf 